Article

\title{
Analysis of Encystment, Excystment, and Cyst Structure in Freshwater Eutardigrade Thulinius ruffoi (Tardigrada, Isohypsibioidea: Doryphoribiidae)
}

\author{
Kamil Janelt * and Izabela Poprawa *(D) \\ Institute of Biology, Biotechnology and Environmental Protection, Faculty of Natural Sciences, University of \\ Silesia in Katowice, Bankowa 9, 40-007 Katowice, Poland \\ * kamil.janelt@gmail.com (K.J.); izabela.poprawa@us.edu.pl (I.P.)
}

Received: 20 December 2019; Accepted: 2 February 2020; Published: 4 February 2020

check for updates

\begin{abstract}
Encystment in tardigrades is relatively poorly understood. It is seen as an adaptive strategy evolved to withstand unfavorable environmental conditions. This process is an example of the epigenetic, phenotypic plasticity which is closely linked to the molting process. Thulinius ruffoi is a freshwater eutardigrade and a representative of one of the biggest eutardigrade orders. This species is able to form cysts. The ovoid-shaped cysts of this species are known from nature, but cysts may also be obtained under laboratory conditions. During encystment, the animals undergo profound morphological changes that result in cyst formation. The animals surround their bodies with cuticles that isolate them from the environment. These cuticles form a cuticular capsule (cyst wall) which is composed of three cuticles. Each cuticle is morphologically distinct. The cuticles that form the cuticular capsule are increasingly simplified. During encystment, only one, unmodified and possibly functional buccal-pharyngeal apparatus was found to be formed. Apart from the feeding apparatus, the encysted specimens also possess a set of claws, and their body is covered with its own cuticle. As a consequence, the encysted animals are fully adapted to the active life after leaving the cyst capsule.
\end{abstract}

Keywords: Thulinius ruffoi; diapause; encystment; cyst

\section{Introduction}

In the environment, many changes may be experienced as stress factors by living organisms. Animals have developed various mechanisms to protect them from negative effects of stressors. Hypometabolic states are seen as a defense in stress responses in many metazoans [1,2]. Moreover, tardigrades developed mechanisms that allow them to withstand unfavorable environmental conditions [3-5]. Tardigrades are worldwide occurring micrometazoans that can be found in varied environments. They occupy marine, brackish, and freshwater (lotic and lentic) habitats. These animals can also be found in limnoterrestrial and terrestrial habitats as well. To be active they need at least a thin layer of water-even in terrestrial environments. Tardigrades have captured the attention of researchers due to their extraordinary abilities [5,6]. Today, these animals are a source of information with great potential for medicine, tissue engineering, pharmacology, astrobiological studies, etc. [7-11]. Cryptobiosis and diapause are known as dormancy states in tardigrades [6]. The former is a quick response to sudden changes in the environment which means that it is directly caused by the environmental stressors. In contrast, the latter is seen as controlled by exogenous and endogenous stimuli $[3,6,12]$ however, the cyst formation is not a direct response to changes in the environment. Cryptobiosis is known from many species of tardigrades, mostly terrestrial, where they are more often exposed to unfavorable conditions. Four types of cryptobiotic states have been 
described for tardigrades: Anhydrobiosis, anoxybiosis, cryobiosis, and osmobiosis [5]. Diapause is represented by encystment and cyclomorphosis [12]. In spite of quite well known cryptobiotic states in tardigrades (especially anhydrobiosis and cryobiosis), knowledge about encystment is poor $[3,13,14]$. Encystment in tardigrades is also seen as a kind of epigenetic phenotypic plasticity, closely linked to the molting process that evolved to withstand unfavorable environmental conditions [6,12]. An ability to form cysts has been noted in some freshwater, bryophilous, and soil tardigrades [14]. Recently, Clausen et al. [15] described the cysts in the marine heterotardigrade Echiniscoides sigismundi. Within the order Isohypsibioidea, an ability to form cysts has been reported in several representatives [16-23] including in Thulinius ruffoi [24]. In this paper, we analyze the encystment and the excystment process in the freshwater tardigrade T. ruffoi and describe the structure and morphology of the cysts using varied methods and techniques. Moreover, a comparative, morphological analysis of the buccal-pharyngeal apparatus between encysted and nonencysted animals was performed.

\section{Materials and Methods}

\subsection{Material}

Specimens of T. ruffoi (Thu.ruf_PL.014) that were used in this study were kindly provided by the Michalczyk Lab (Jagiellonian University, Cracow, Poland). Specimens were cultured under laboratory conditions on Petri dishes and plastic 24-well plates (Institute of Biology, Biotechnology and Environmental Protection, University of Silesia in Katowice, Katowice, Poland). Before placing animals on the Petri dishes or 24-well plates, the bottoms were scratched, washed with distilled water, and flooded with a culture medium (distilled water and Żywiec Zdrój mineral water, 1:1). The animals were fed with a mixture (1:1) of Chlorella sp. and Chlorococcum sp. ad libitum and kept at $19{ }^{\circ} \mathrm{C}$ and room temperature (RT about $25^{\circ} \mathrm{C}$ ). Cysts of $\mathrm{T}$. ruffoi used in this study were obtained under laboratory conditions as follows. Scratched, plastic 24-well plates were washed with distilled water, then flooded with culture medium and a mixture of algae added. Randomly selected, nonencysted, adult animals were then added, one specimen per well. Plates were transferred to lower temperatures with a mean of 6.5 and $8{ }^{\circ} \mathrm{C}$. At both temperatures, cysts were formed. Observations were made using a stereoscopic microscope (Olympus SZ40) and at room temperature for the shortest possible time. To interrupt the encystment artificially, selected cysts were permanently transferred to a higher temperature (RT).

\subsection{Methods}

An Olympus BX60 microscope was used for analysis of the structure of the cyst and cuticular capsules using brightfield (BF) and differential interference contrast (DIC). Moreover, filters for detecting UV autofluorescence according to Perry et al. [25] were used in the analysis. Permanent slides were prepared using Hoyer's mounting medium (prepared according to Morek et al. [26] and closed with a coverslip. Nonencysted specimens were investigated using the same microscope and techniques. Encysted and nonencysted animals (in vivo), as well as empty cuticular capsules were also observed in a drop of water between a slide and a coverslip. Additionally, some cysts were dissected by rolling the cyst between the slide and a coverslip carefully until the cuticular capsule broke and the animals were pulled out. Ten empty cuticular capsules, 20 encysted and 20 nonencysted animals were used.

Material for semi- and ultra-thin sections was prepared as follows. Eight cysts and four empty cuticular capsules of T. ruffoi were washed a few times with distilled water and fixed with $2.5 \%$ glutaraldehyde $\left(4^{\circ} \mathrm{C}\right)$. Then, the material was washed three times $(3 \times 30 \mathrm{~min}$ each, $\mathrm{RT})$ in $0.1 \mathrm{M}$ phosphate buffer $(\mathrm{pH}=7.4)$, postfixed in $2 \%$ osmium tetroxide in phosphate buffer $(2 \mathrm{~h}, \mathrm{RT})$, and washed in phosphate buffer $(3 \times 10 \mathrm{~min}$ each, RT). Then, material was dehydrated in a graded ethanol series (30\%, $2 \times 50 \%, 70 \%, 90 \%, 96 \%, 4 \times 100 \%, 15 \mathrm{~min}$ each, RT), transferred to a solution of $100 \%$ ethanol and acetone $(1: 1,15 \mathrm{~min}, \mathrm{RT})$, washed in acetone $(2 \times 10 \mathrm{~min}, \mathrm{RT})$, and then transferred to a solution of epoxy resin and acetone (1:1, 1.5 h, RT). After the evaporation of acetone (overnight, RT), 
material was embedded in epoxy resin (Epoxy Embedding Medium Kit; Sigma). The resin in which the material was embedded was polymerized at $60^{\circ} \mathrm{C}$. Semi- and ultra-thin sections were cut on a Leica Ultracut UCT25 ultramicrotome. Semi-thin cross-sections of the cysts and empty cuticular capsules were stained with $1 \%$ methylene blue in $1 \%$ borax, mounted with a DPX medium and analyzed using an Olympus BX60 microscope. Ultra-thin sections were counterstained with uranyl acetate and lead citrate and analyzed using a Hitachi $\mathrm{H} 500$ transmission electron microscope at $75 \mathrm{kV}$.

For analysis in scanning electron microscopy, eight cysts and four empty cuticular capsules were cleaned by washing several times with distilled water and fixed in $1.5 \%$ glutaraldehyde. Material were washed three times with distilled water $(3 \times 10 \mathrm{~min})$ and postfixed with $2 \% \mathrm{OsO}_{4}(1 \mathrm{~h}, \mathrm{RT})$, then washed with distilled water $(3 \times 10 \mathrm{~min})$ and dehydrated using a graded ethanol series $(10 \%-100 \%$, with 10\% increase, 2 min each) without an acetone series. Then, material was dried in a critical point dryer (CPD-2 Pelco) and placed on stubs with adhesive carbon tabs and covered with an ultrathin layer of chromium using the sputter coater Quorum 150T ES Plus. Material was analyzed using Hitachi UHR FE-SEM SU 8010 and Phenom XL scanning electron microscopes. All used equipment is available at the Institute of Biology, Biotechnology and Environmental Protection (Faculty of Natural Sciences, University of Silesia in Katowice, Katowice, Poland).

\section{Results}

\subsection{Encystment and Excystment}

At the beginning of the incubation at tested, low temperatures, the animals were active. They were moving and eating, with the result that the midgut contents were visible. However, some of them died within a few days of transferring them to lower temperatures (Figure 1A).

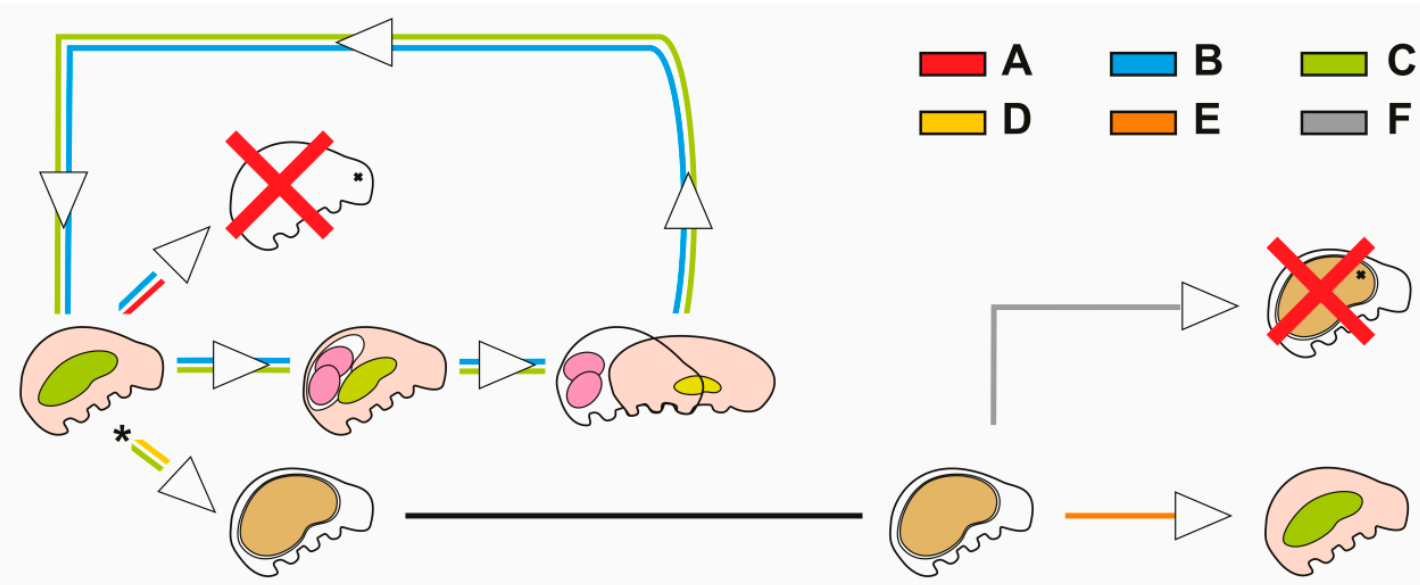

Figure 1. Scheme of the general behavior pathways related to cyst dynamics. (A) Animal's death within a few days of being transferred to a low temperature; (B) animal's death after one or several reproductive cycles since being transferred to a low temperature; (C) cyst formation by specimens which have undergone one or several reproductive cycles since being transferred to low temperature;

(D) cyst formation by specimens that have not reproduced since being transferred to low temperature;

(E) leaving the cuticular capsule/free-living animal; (F) animal's death before the cuticular capsule abandonment. Period of reproduction arrest (asterisk).

Simplex forms (or in other words-animals on the simplex stage) are characterized by the lack of sclerified elements of the buccal-pharyngeal apparatus and the absence of the cuticular lining of the esophagus. These forms were observed during the active life of the animals. Single separated specimens were able to reproduce via parthenogenesis (Figure 1B,C) and eggs within exuviae were present in further observations. The specimens reproduced once or a few times. After that, specimens died (Figure 1B) or formed cysts (Figure 1C). However, before cyst formation, a period when the animals 
did not reproduce was observed. During that time, animals were eating intensively. This period was observed to begin either after transferring the animal to the low temperature (Figure 1D) or after one or a few reproductive cycles (Figure 1C). The first cysts were formed at least 14-15 days after the animals were transferred to lower temperatures. However, cyst formation often occurred after more than a month. Animals did not enter into encystment at the same time, which meant that cysts were formed after different times of incubation under low temperatures. The gut of some specimens that formed cysts was emptied by defecation before cyst formation.

During encystment, the appearance of an animal changed significantly (Figure 2A,B).
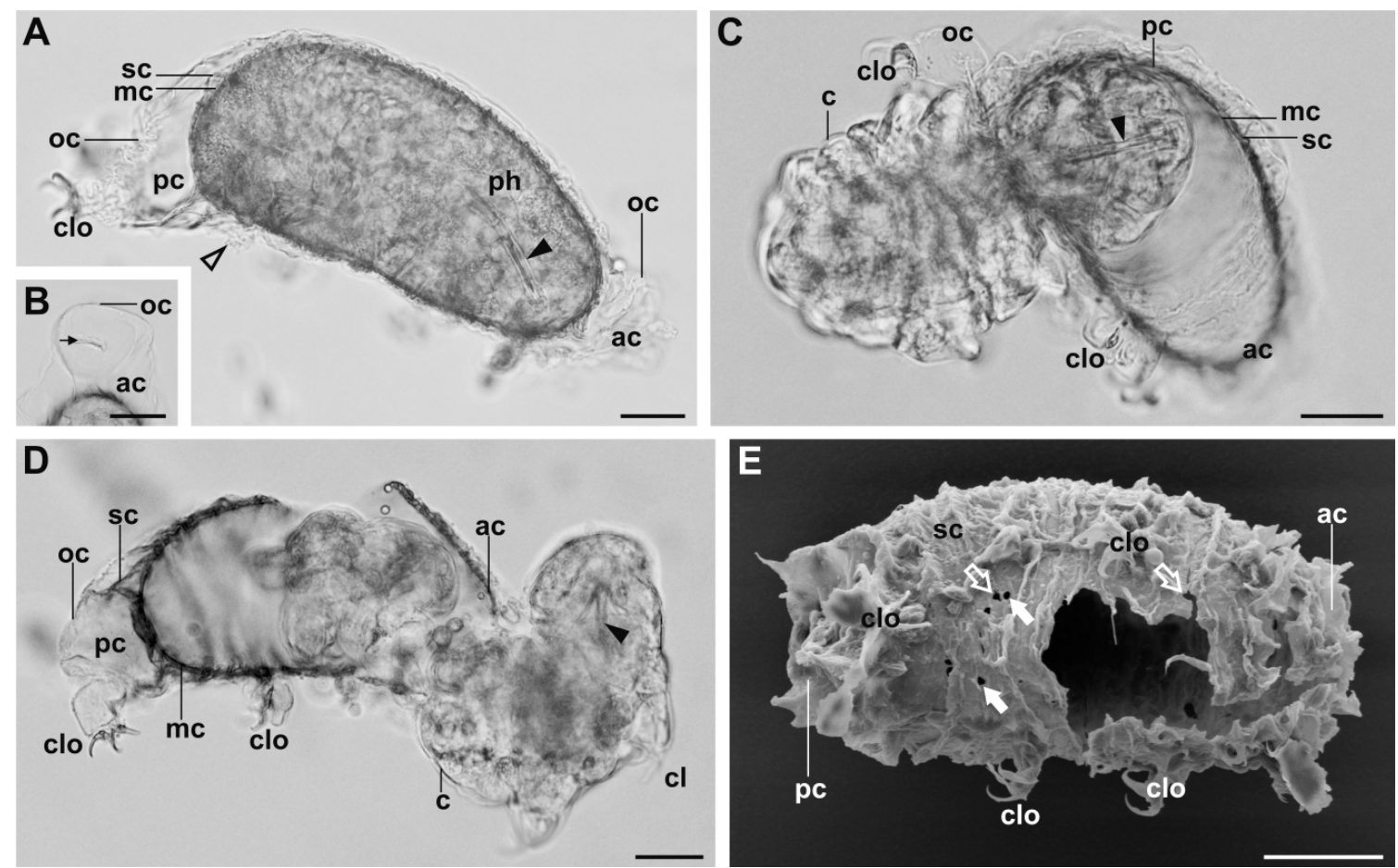

Figure 2. Cyst structure and excystment. (A) Twenty four-hour old cyst in vivo, lateral view, BF; (B) anterior part of the cyst in vivo, ventro-lateral view, BF; (C,D) excystment; (C) leaving the cuticular capsule through the posterior part of the cuticular capsule, in vivo, BF; (D) leaving the cuticular capsule through the anterior part of the cuticular capsule, in vivo, BF; (E) empty cuticular capsule, ventro-lateral view, SEM. Scale bars $25 \mu \mathrm{m}$. Note that the old cuticle is only in the form of the remains of cuticle with claws. Anterior part of the cyst/cuticular capsule (ac); cuticle of the animal (c); claws of the animal (cl); claws of the old cuticle (clo); mummy cuticle (mc); old cuticle (oc); posterior part of the cyst/cuticular capsule (pc); pharynx (ph); sarcophagus cuticle (sc); cuticle of the hindgut (empty arrowhead); buccal-pharyngeal apparatus of the animal (filled arrowhead); increase in damage (thick empty arrow); round holes made by claws (thick filled arrow); closed mouth opening of the old cuticle (thin arrow).

At this time, discharge of the sclerified elements of the buccal-pharyngeal apparatus together with the cuticular lining of the esophagus occurred and the animals entered into the simplex stage. The animals were unable to eat anymore. The locomotor activity of the animal decreased until it stopped completely in one place. The animal surrounded its body with cuticles together with the reduction of the body size by its contraction and buccal-pharyngeal apparatus resynthesis. As a result, the animal was enclosed within the cuticular capsule (Figure 2A). During this time, animals could not move, eat, or reproduce. Cysts with (Video S1) or without (Figure 2A) content inside the midgut were observed. The encystment could be interrupted by the animals themselves or under laboratory conditions. The first was observed in some encysted specimens which spontaneously interrupted the encystment 
while still at low temperature. The second may have been caused by the transfer of the cyst from a lower to a higher temperature.

Based on the possibility of inducing encystment termination (excystment), it was possible to study this process. In encysted animals which were transferred to room temperature, movements inside the cuticular capsule were observed (Video S1). Movements of the body, including the movement of the legs with their claws caused the breaking of the cuticular capsule (Figure 2C-E). The claws could pierce the cuticles making characteristic perforations. Then, the increase in cracks could cause greater damage weakening the capsule, making it easier for the animal to leave the capsule (Figure 2E). After about 2-3 days, at room temperature, the animals started to abandon the cuticular capsule or were already moving freely in the environment after leaving the capsule (Figures $1 \mathrm{E}$ and $2 \mathrm{C}, \mathrm{D}$ ). Encysted specimens that after their permanent transfer to room temperature did not abandon the cuticular capsule (for more than a week) were considered dead (Figure 1F).

\subsection{Cuticular Capsule}

Animals surrounded their bodies with three cuticles that formed a cyst capsule (Figure 2A-D, Figures 3-5).
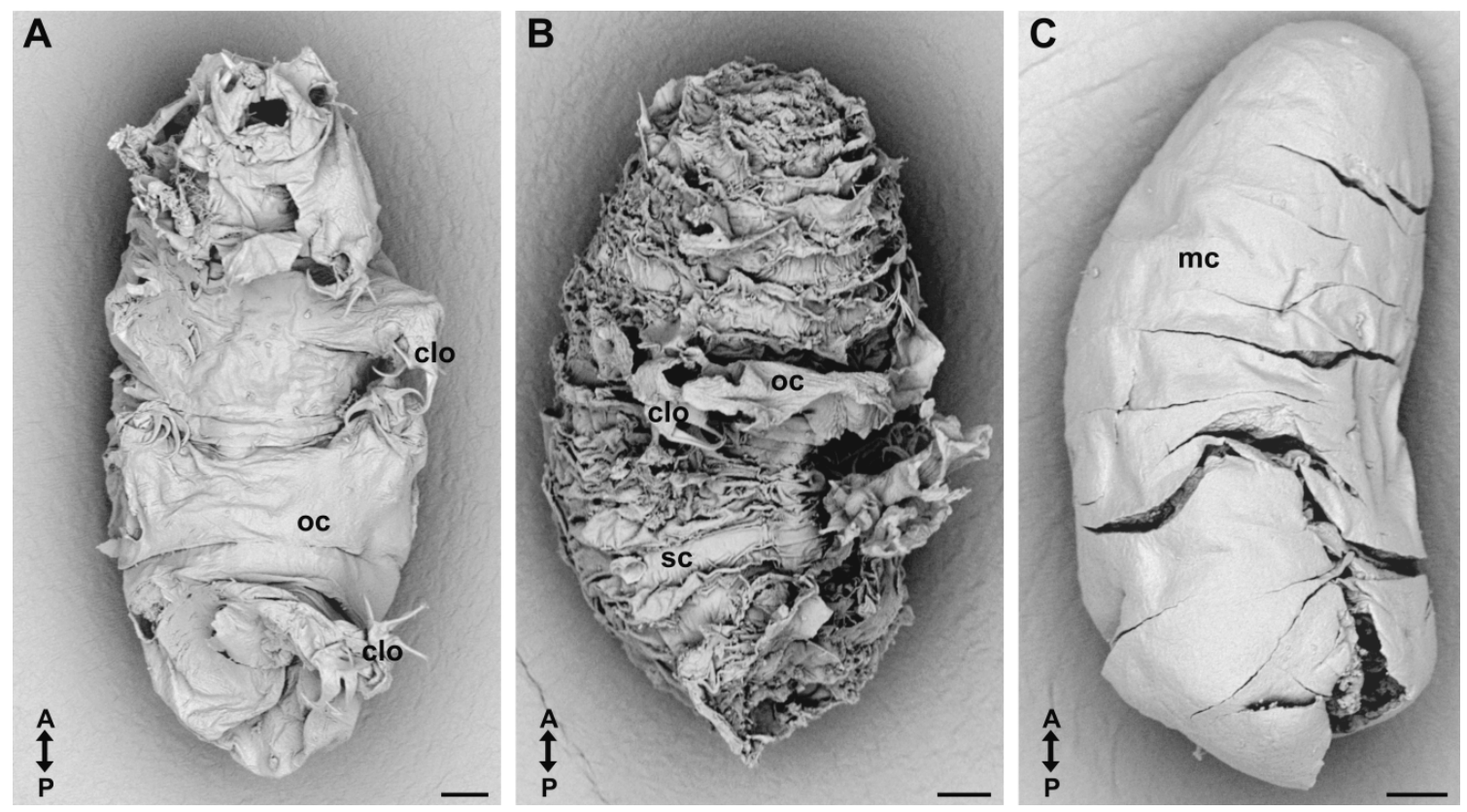

Figure 3. Cuticles of the cuticular capsule, SEM. (A) Old cuticle (external cuticle), ventral view; (B) sarcophagus cuticle (middle cuticle) with the remains of the old cuticle with claws, ventro-lateral view; (C) mummy cuticle (inner cuticle). Scale bars $10 \mu \mathrm{m}$. Old cuticle (oc); claws of the old cuticle (clo); mummy cuticle (mc); sarcophagus cuticle (sc). Note that A-P indicates anterior to posterior direction. 

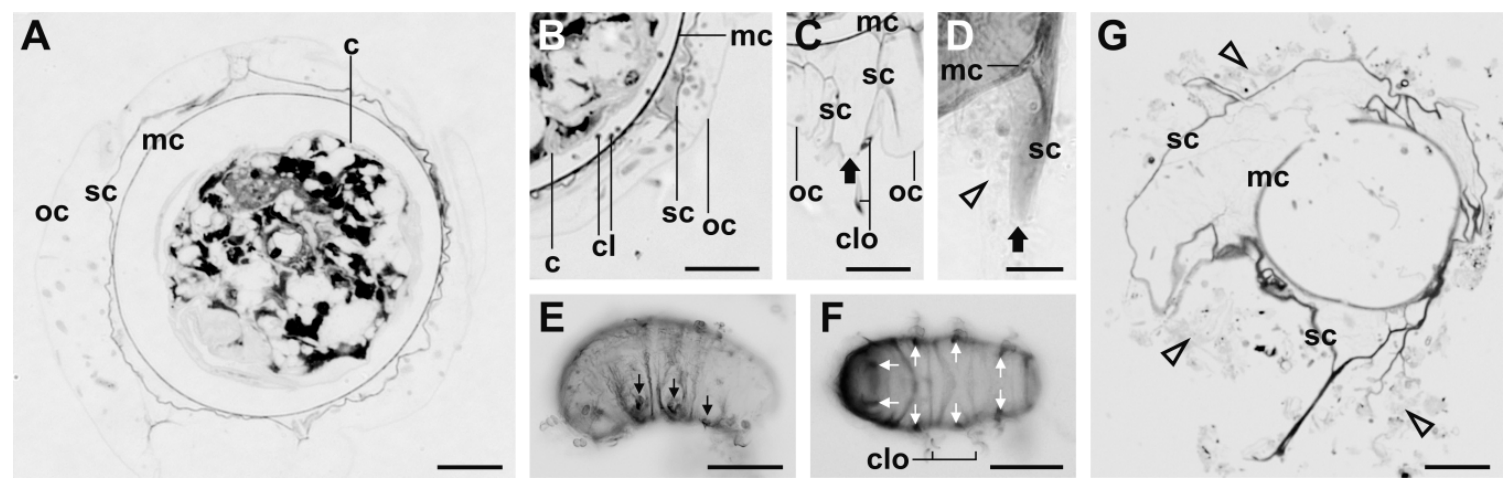

Figure 4. Cuticular capsule of the cyst, BF. (A-C) Cross-section through the cyst; (D-G) empty cuticular capsules; (C-F) legs of the sarcophagus cuticle; (C) cross-section through the leg of the sarcophagus cuticle; (D) fourth leg of the sarcophagus cuticle; (E) legs of the sarcophagus cuticle, lateral view; (F) legs of the sarcophagus cuticle, ventral view; (G) cross-section through the empty cuticular capsule. Scale bars $10 \mu \mathrm{m}$ in A,B,C,D,G and $50 \mu \mathrm{m}$ in E,F. Cuticle of the animal (c); claws of the animal (cl); claws of the old cuticle (clo); mummy cuticle (mc); old cuticle (oc); sarcophagus cuticle (sc); remains of the old cuticle (empty arrowhead); small hole at the end of the sarcophagus cuticle's leg (thick filled arrow); legs of the sarcophagus cuticle (thin arrow).
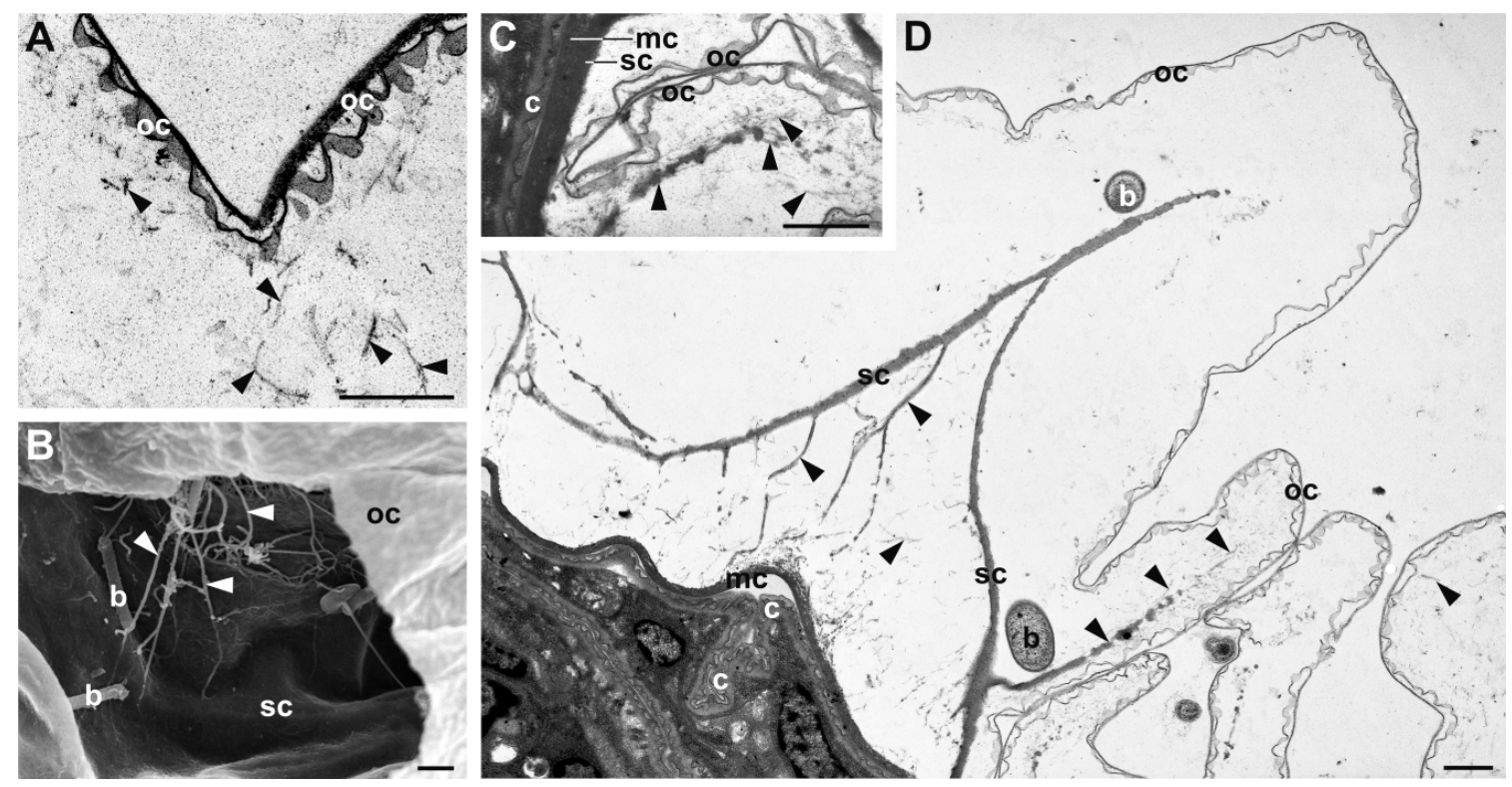

Figure 5. Cyst and its cuticles. Cuticular capsule of the cyst, TEM (A,C,D), and SEM (B). Scale bars 1 $\mu \mathrm{m}$. Bacteria (b); cuticle of the animal (c); mummy cuticle (mc); old cuticle (oc); sarcophagus cuticle (sc); cuticular connections (filled arrowhead).

Additionally, the encysted animal possessed its own cuticle (Figure 4A,B and Figure 5C,D). The cyst capsule (from outside to inside) was formed by an old cuticle (outer cuticle), sarcophagus cuticle (middle cuticle), and mummy cuticle (inner cuticle). This structure of the cuticular capsule was observed in the 24-h old cysts (Figure 2A). Each of these three cuticles was different from each other (Figure 3). In the old cuticle, the mouth opening was closed (Figure 2A) and shedding of the hindgut cuticle could be observed (Figure 2A). The legs of the old cuticle ended with claws (Figure 2A,C,D, Figures $3 \mathrm{~A}$ and $4 \mathrm{C}$ ). The legs of the sarcophagus cuticle were developed as cuticular cones without claws; however, a small hole was present at the end of each cone (Figure 4C-F). These cones were located in the regions where the legs of the old cuticle had been (Figure 4C-F). On the surface of this cuticle numerous folds and wrinkles were observed (Figures 2E and 3B). The mummy cuticle 
did not possess legs (Figure 3C). Between the old cuticle and the sarcophagus cuticle, a network of numerous cuticular connections of different thickness was observed (Figure 5). A similar network of connections was also noted between the sarcophagus and mummy cuticles (Figure 5D). Cysts without the continuous layer of the old cuticle were also observed. When the old cuticle was falling apart, the remains of this cuticle and claws could still be observed on the surface of the sarcophagus cuticle (Figures 2E, 3B and 4G). The cuticle that covered the body of the encysted animals was developed as in nonencysted animals. The animals enclosed within the cuticular capsule also possessed, in addition to their own cuticle, a set of claws what was confirmed using optical microscopy for analysis of the cysts in toto (Figure 2C,D and Figure 6A), as well as on the cross-sections through the cyst (Figure 4B) and based on the specimens obtained by the cysts' dissection and encystment interruption.
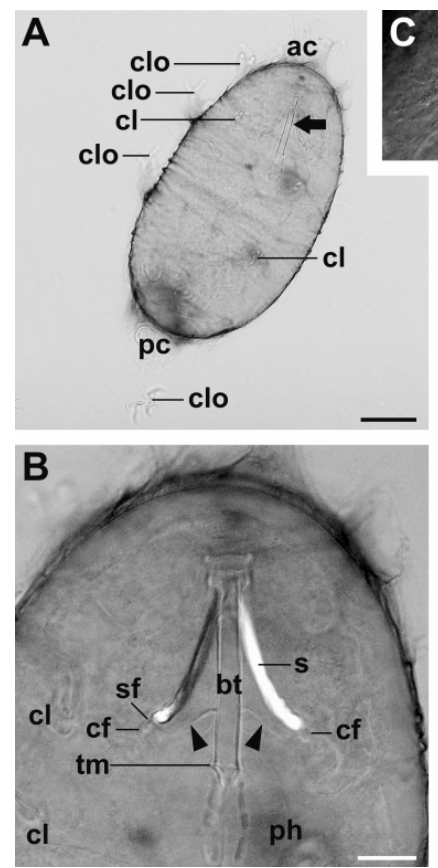
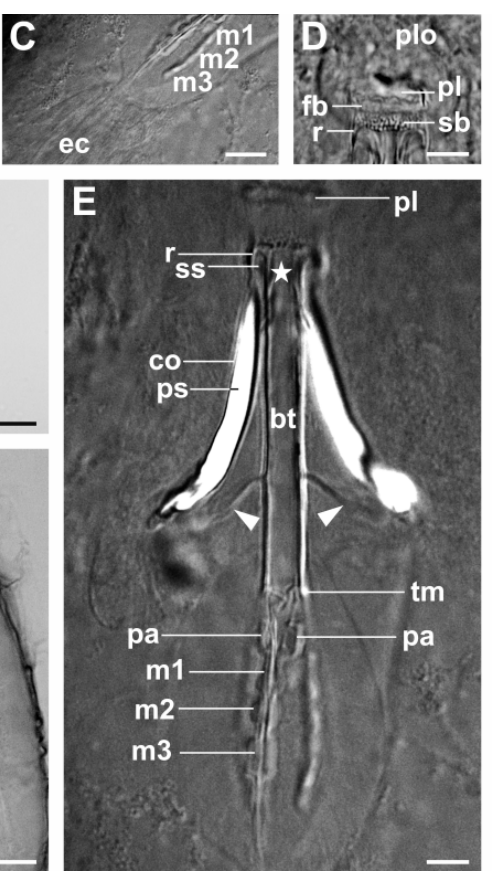
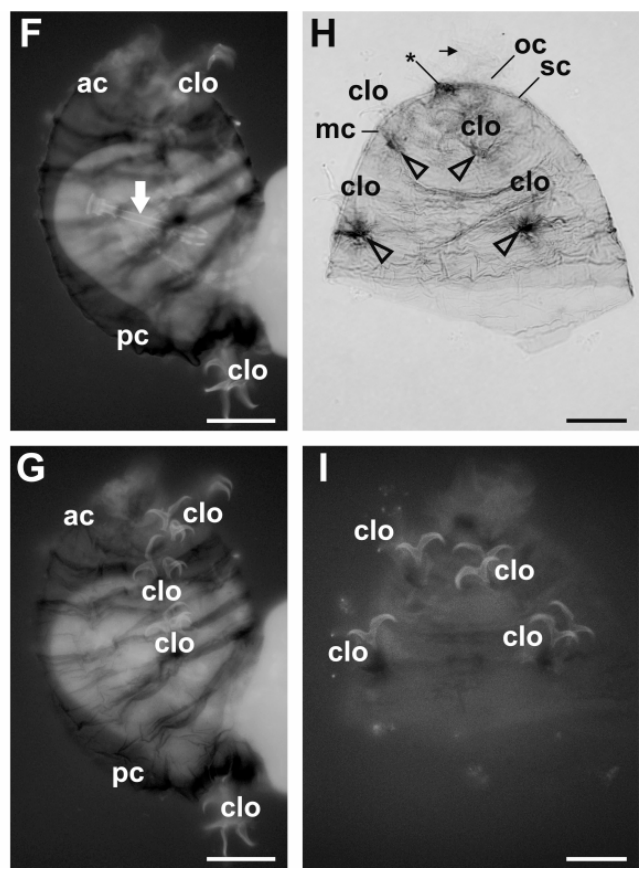

Figure 6. The buccal-pharyngeal apparatus and claws of the cyst. (A-E) The buccal-pharyngeal apparatus of the encysted animal, DIC; (A) cyst in toto; (B) an enlarged anterior part of the cyst (from A) with the buccal-pharyngeal apparatus. Note that only one buccal-pharyngeal apparatus is visible; (C) posterior part of the buccal-pharyngeal apparatus with cuticular lining of the esophagus, cyst dissection; (D) peribuccal structures and an anterior part of the buccal-pharyngeal apparatus, cyst dissection; (E) details of the feeding apparatus, cyst dissection; (F-I) cuticular structures; (F,G) excystment; (F) autofluorescence of the animal's buccal-pharyngeal apparatus; (G) autofluorescence of the cuticular capsule's claws; $(\mathbf{H}, \mathbf{I})$ isolated anterior part of the cuticular capsule, cyst dissection; $(\mathbf{H})$ cuticles and claws of the cuticular capsule, DIC; (I) autofluorescence of the cuticular structures. Scale bars $30 \mu \mathrm{m}$ in A,F,G, $10 \mu \mathrm{m}$ in B,C, $5 \mu \mathrm{m}$ in D,E, and $20 \mu \mathrm{m}$ in H,I. Note that only claws show autofluorescence in the anterior part of the cuticular capsule. No additional buccal-pharyngeal apparatuses are detected between the cuticles of the cuticular capsule. Anterior part of the cyst/cuticular capsule (ac); buccal tube (bt); condyle of the furca (cf); claws of the animal (cl); claws of the old cuticle (clo); stylet coat (co); esophagus cuticle (ec); first band of teeth (fb); three macroplacoids in a row (m1,m2,m3); mummy cuticle (mc); old cuticle (oc); pharyngeal apophysis (pa); posterior part of the cyst/cuticular capsule (pc); pharynx (ph); peribuccal lamellae (pl); peribuccal lobes (plo); piercing stylet (ps); rod-shaped thickening (r); stylet (s); second band of teeth (sb); sarcophagus cuticle (sc); stylet furca (sf); stylet sheath (ss); buccal tube margin (tm); putative modified mouth part of the sarcophagus cuticle (asterisk); cuticular legs of the sarcophagus cuticle (empty arrowhead); stylet support (filled arrowhead); buccal crown (star); buccal-pharyngeal apparatus of the encysted animal (thick filled arrow); closed mouth opening of the old cuticle (thin arrow). 
The cuticular capsule isolated the animals from the environment. In nondamaged cysts (where the continuity of all cuticles of the cuticular capsule was not broken) the bacteria from the environment were observed outside the old cuticle, as well as in the space between the old cuticle and sarcophagus cuticle (Figure 5B,D). Bacteria were not observed in the spaces between the animal and the most inner cuticle of the capsule, the mummy cuticle.

\subsection{Buccal-Pharyngeal Apparatus}

The cyst formation was preceded by the simplex stage where the buccal-pharyngeal apparatus together with the cuticle lining of the esophagus was ejected outside the body and the mouth opening was closed (Figure 2B). However, during cyst formation this feeding apparatus and esophagus lining was resynthesized together with a new set of claws (Figure 2A,C,D, Figures 4B and 6A-F). Only one buccal-pharyngeal apparatus was observed in the cysts of $T$. ruffoi despite the use of various techniques of optical microscopy (Figures 2A and 6). In 24-h old cysts, the buccal-pharyngeal apparatus appeared completely formed (Figure 2A). Moreover, in the older cysts (Figure 6A-F), a complete, single buccal-pharyngeal apparatus was observed. In the animals closed inside the cyst, peribuccal structures around the mouth such as peribuccal lobes and peribuccal lamellae were observed (Figure 6D,E). The buccal armature (oral cavity armature) was composed of two bands of teeth where the teeth of the second band were larger than those which formed the first band (Figure 6D). The buccal crown surrounded externally the wall of the anterior part of the buccal tube (Figure 6E). The most posterior end of the buccal tube was located within the pharynx. The buccal tube ended with an enlarged margin (Figure 6B,E). Within the pharynx, three pharyngeal apophyses that alternated with three rows of symmetrical placoids were located. In each row of placoids, three macroplacoids were present, the middle one being the smallest (Figure 6E). On both sides of the buccal tube, elements of the stylet system were observed. This part of the buccal-pharyngeal apparatus was formed by two stylets and two stylet supports (Figure 6B,E). Each stylet was composed of a piercing stylet located inside a stylet coat. Anteriorly, the stylet coat was formed as a stylet sheath (Figure 6E) and posteriorly as a stylet furca (Figure 6B). Each stylet sheath was laterally reinforced by a thin, rod-shaped cuticular thickening that was anteriorly connected to the buccal crown (Figure 6D,E). The stylet furca was branched and each branch ended with a condyle. Two stylet supports located on both sides of the buccal tube connected the posterior part of the stylet coat with the buccal tube. The distal extremities of the stylet supports were bifurcated and fused to the arc between two condyles of the stylet furca. However, the proximal end was connected with the buccal tube (Figure 6B,E). Comparative, morphological analysis of the buccal-pharyngeal apparatus between nonencysted and encysted animals showed that the feeding apparatus of the cysts had no morphological modifications. The apparatus did not show any signs of simplification in its morphology (Figure 6A-E). The buccal-pharyngeal apparatus was located inside the animal in a typical place (Figure 2A,C,D and Figure 6A,B,F). Morphological analysis (Figure 6A-E), as well as stylet system movements of this apparatus (Video S1) indicated that this apparatus was functional and not modified. No additional buccal-pharyngeal apparatuses were found between the cuticles of the cuticular capsule despite the use of various techniques of optical microscopy (Figures 2A and 6A,B,F-I).

\section{Discussion}

Dormancy in tardigrades [6] and some other groups of invertebrates such as rotifers [27,28], nematodes [29], bryozoans [30], insects [31], or crustaceans [32] can be seen as an adaptive strategy to survive in unfavorable conditions. Encystment (a form of diapause) in tardigrades is still poorly understood despite the fact that an ability to form cysts was found among several representatives of Heterotardigrada and Eutardigrada classes [14-24,33-43]. Murray [38] also mentioned cysts of the genus Milnesium that are classified into the class Apotardigrada. Although the ability to form cysts has been recorded in several genera, many of these descriptions do not contain information about the cysts' formation and their structure. These aspects were studied in eutardigrades such as Dactylobiotus 
macronyx [33], Dactylobiotus dispar [34,37,44-46], Dactylobiotus parthenogeneticus [14], Bertolanius nebulosus [41,47], Bertolanius volubilis [14], and Pseudobiotus megalonyx [16]. Some aspects were also studied by Clausen et al. [15], who described cyst formation in the tidal heterotardigrade Echiniscoides sigismundi. Encystment is seen as controlled by endogenous but also exogenous stimuli $[3,6,12]$. Different environmental factors are suggested to be involved in encystment such as osmotic stress, $\mathrm{pH}$ alterations, low oxygen tension, reserve depletion, and temperature variation $[3,15,16,18,22,37,41,44,45]$. T. ruffoi is a freshwater tardigrade, and cysts of this species have been found in nature [24]. However, the present study shows that they can also be obtained under laboratory conditions. Schill et al. [24] suggested that the encystment in this species may be triggered by external factors such as temperature or food availability and be a survival strategy. We agree that temperature as an abiotic (environmental) factor may be involved in cyst formation. In the tested low temperatures, specimens of T. ruffoi formed cysts.

Cysts were formed by the animals after variable incubation times at low temperature. During active life at lower temperature animals are able to move, eat, and reproduce, which is not possible during encystment. Some specimens did not reproduce at the beginning of incubation at low temperature and after some time, during which they ate intensively, they formed cysts. Moreover, some animals that reproduced at these low temperatures also formed cysts. However, similarly to the previous case, before cyst formation they stopped reproducing and ate intensively. The reason for these behaviors may be related to the high energetic cost of reproduction and cyst formation. In addition, eggs have never been found in the encysted specimens of T. ruffoi. Before cyst formation, animals accumulated the reserve materials to be a source of energy during encystment, which has also been observed for other species $[16,44,45]$. The reproductive arrest observed before cyst formation in T. ruffoi could possibly allow accumulation of larger amounts of reserve material that would be a source of energy during ongoing encystment. As an adaptation to survive for many months without food supplied from the environment, the energy consumption must be limited. Encystment is a process in which energetic costs seem to be reduced by formation of simplified nonfunctional structures [6]. The formation of the simplified structures, together with the lowering of the metabolic rate of the encysted animals [48], reduces the energy consumption during encystment.

During cyst formation, specimens of T. ruffoi surround their body with three cuticles, which together form the cuticular capsule of the cyst. These cuticles (from outside to inside) are named the old cuticle, sarcophagus cuticle, and mummy cuticle, using terminology proposed by Hansen and Katholm [47] and Guidetti et al. [14]. The cuticles of the cyst capsule are increasingly simplified (from outside to inside). The most external cuticle of the cuticular capsule is the old cuticle. Here, the closed mouth opening, shed hindgut cuticle, and the legs terminating with claws can be observed. The sarcophagous cuticle has a folded structure. The legs of this cuticle are visible as clawless cones under the legs of the old cuticle and they terminate with small holes. The innermost cuticle of the cuticular capsule has no legs. Cuticles of the cyst capsule are connected by a network of cuticular connections.

An interesting aspect of the encystment process concerns the changes related to the buccal-pharyngeal apparatus. Studies by Guidetti et al. [14] showed that in encysted specimens of $D$. parthenogeneticus after the simplex stage, a modified buccal-pharyngeal apparatus is formed two times and seems to be nonfunctional. After discharging them, an unmodified feeding apparatus is formed. In species of Bertolanius (B. nebulosus, B. volubilis, and B. weglarskae) two cyst types were noted $[14,41-43,47]$ but only in B. volubilis and only in "type 2" cysts was the synthesis of one modified buccal-pharyngeal apparatus after the simplex stage described. After discharging this modified one, another unmodified feeding apparatus is formed. The "type 1" cysts of B. volubilis do not synthesize the modified buccal-pharyngeal apparatus but only a single, unmodified buccal-pharyngeal apparatus is formed after the simplex stage [14]. Similarities between the cysts of $D$. parthenogeneticus and the "type 2" cysts of $B$. volubilis were observed, although with the reservation that the cyst of this first one is more complex [14]. In contrast to data presented by Guidetti et al. [14] for cysts of 
D. parthenogeneticus or "type 2" cysts of B. volubilis, in T. ruffoi only one buccal-pharyngeal apparatus is synthesized during encystment. Its morphological analysis showed that it looks like ones found in nonencysted animals. The presence of modified buccal-pharyngeal apparatuses was not found in cysts of this species despite using various investigative methods. Moreover, its movements after transferring the cysts to higher temperatures indicated functional efficiency and suggests that this structure is helpful in the interruption of the cyst capsule cuticles' continuity during excystment, as well as being useful after leaving the cuticular capsule. Therefore, not only body movements including movements of the legs terminated with claws but also movements of the feeding apparatus may be useful during breaking of the cyst capsule.

In T. ruffoi, formation of the normally developed cuticle, claws, and a single, functional, nonmodified feeding apparatus seems to reduce energetic costs to the necessary minimum and the animal is fully prepared for life after encystment termination and leaving the cuticular capsule of the cyst. As a result, T. ruffoi can immediately start eating and replenish its energy. Still many aspects of the encystment process are not known or clear. More research on this process is needed to better understand the encystment in tardigrades.

\section{Conclusions}

Our conclusions from this study are as follows: (1) T. ruffoi is able to form cysts. (2) Cysts may be obtained under laboratory conditions. (3) The cyst capsule inside which the animal is closed is composed of three cuticles. (4) Cuticles of the cyst capsule are increasingly simplified (from outside to inside). (5) The animal inside the cyst is covered with a cuticle which develops like nonencysted specimens of this species and possesses claws. (6) The animal produces only one, functional and unmodified buccal-pharyngeal apparatus.

Supplementary Materials: The following are available online at http://www.mdpi.com/1424-2818/12/2/62/s1, Video S1: Body and buccal-pharyngeal apparatus movements inside the cyst of T. ruffoi.

Author Contributions: Conceptualization, investigation, data analysis, methodology, writing—original draft preparation, and review and editing, K.J.; visualization, K.J. and I.P.; writing-review and editing and supervision, I.P. All authors have read and agreed to the published version of the manuscript.

Funding: This research received no external funding.

Acknowledgments: We are grateful to the Michalczyk Lab (Jagiellonian University, Cracow, Poland), which kindly provided the strain of T. ruffoi (Thu.ruf_PL.014). Especially we would like to thank Daniel Stec and Mateusz Sobczyk (Jagiellonian University, Cracow, Poland). Moreover, we would like to thank Dr. Danuta Urbańska-Jasik, Dr. Łukasz Chajec, Dr. Jagna Karcz, and Natalia Kaszyca-Taszakowska (University of Silesia in Katowice, Poland) for their technical assistance. The authors are deeply indebted to Richard Ashcroft, biomedical editor (http://www.anglopolonia.com/home.html), for improving the English style.

Conflicts of Interest: The authors declare no conflict of interest.

\section{References}

1. Padilla, P.A.; Ladage, M.L. Suspended animation, diapause and quiescence. Cell Cycle 2012, 11, 1672-1679. [CrossRef]

2. Gorr, T.A. Hypometabolism as the ultimate defence in stress response: how the comparative approach helps understanding of medically relevant questions. Acta Physiol. 2017, 219, 409-440. [CrossRef] [PubMed]

3. Guidetti, R.; Boschini, D.; Altiero, T.; Bertolani, R.; Rebecchi, L. Diapause in tardigrades: a study of factors involved in encystment. J. Exp. Biol. 2008, 211, 2296-2302. [CrossRef]

4. Møbjerg, N.; Halberg, K.A.; Jørgensen, A.; Persson, D.; Bjørn, M.; Ramløv, H.; Kristensen, R.M. Survival in extreme environments - on the current knowledge of adaptations in tardigrades. Acta Physiol. 2011, 202, 409-420. [CrossRef] [PubMed]

5. Nelson, D.R.; Guidetti, R.; Rebecchi, L. Chapter 17 - Phylum Tardigrada. In Thorp and Covich's Freshwater Invertebrates, 4th ed.; Thorp, J.H., Rogers, D.C., Eds.; Elsevier: London, UK, 2015; Volume 1, pp. 347-380.

6. Guidetti, R.; Altiero, T.; Rebecchi, L. On dormancy strategies in tardigrades. J. Insect Physiol. 2011, 57, 567-576. [CrossRef] [PubMed] 
7. Grohme, M.; Frohme, M.; Schnölzer, M.; Dandekar, T.; Reuter, D.; Schill, R.O. New insights into anhydrobiotic organisms: Perspectives for preservation and stabilization of biological material. Comp. Biochem. Physiol. Part A 2008, 151, 31-36. [CrossRef]

8. Jönsson, K.I.; Rabbow, E.; Schill, R.O.; Harms-Ringdahl, M.; Rettberg, P. Tardigrades survive exposure to space in low Earth orbit. Curr. Biol. 2008, 18, R729-R731. [CrossRef]

9. Schill, R.O.; Mali, B.; Dandekar, T.; Schnölzer, M.; Reuter, D.; Frohme, M. Molecular mechanisms of tolerance in tardigrades: New perspectives for preservation and stabilization of biological material. Biotechnol. Adv. 2009, 27, 348-352. [CrossRef]

10. Varghese, A.C.; Nagy, Z.P.; Agarwal, A. Current trends, biological foundations and future prospects of oocyte and embryo cryopreservation. Reprod. Biomed. Online 2009, 19, 126-140. [CrossRef]

11. Sloan, D.; Batista, R.A.; Loeb, A. The resilience of life to astrophysical events. Sci. Rep. 2017, 7, 5419. [CrossRef]

12. Guidetti, R.; Møbjerg, N. Environmental Adaptations: Encystment and Cyclomorphosis. In Water Bears: The Biology of Tardigrades; Schill, R.O., Ed.; Zoological Monographs; Springer: Cham, Switzerland, 2018; Volume 2, pp. 249-271.

13. Bertolani, R.; Guidetti, R.; Jönsson, K.I.; Altiero, T.; Boschini, D.; Rebecchi, L. Experiences with dormancy in tardigrades. J. Limnol. 2004, 63, 16-25. [CrossRef]

14. Guidetti, R.; Boschini, D.; Rebecchi, L.; Bertolani, R. Encystment processes and the "Matrioshka-like stage" in a moss-dwelling and in a limnic species of eutardigrades (Tardigrada). Hydrobiologia 2006, 558, 9-21. [CrossRef]

15. Clausen, L.K.B.; Andersen, K.N.; Hygum, T.L.; Jørgensen, A.; Møbjerg, N. First record of cysts in the tidal tardigrade Echiniscoides sigismundi. Helgol. Mar. Res. 2014, 68, 531-537. [CrossRef]

16. von Wenck, W. Entwicklungs geschichtliche Untersuchungen an Tardigraden (Macrobiotus lacustris Duj.). Zool. Jahrb. Abt. Für Anat. Ontog. Tiere 1914, 37, 465-514.

17. Marcus, E. Spinnentiere oder Arachoides. IV. Bärtichen (Tardigrada). In Die Tierreich Deutschlands und der angrenzenden Meeresteile; Dahl, F., Ed.; Gustav Fischer: Jena, Germany, 1928; Volume 12, pp. 1-230.

18. Marcus, E. Tardigrada. In HG Bronn's Klassen und Ordnungen des Tierreichs; Bronn, H.G., Ed.; Akademische Verlagsgesellschaft: Leipzig, Germany, 1929; Volume 5, pp. 1-608.

19. Ramazzotti, G. Tardigradi in terreni prativi. Atti Soc. Ital. Sci. Nat. Mus. Civ. Stor. Nat. Milano 1959, 98, 199-210.

20. Manicardi, G.C. Two new species of soil moss eutardigrades (Tardigrada) from Canada. Can. J. Zool. 1989, 67, 2282-2285. [CrossRef]

21. Biserov, V.I. A new genus and three new species of tardigrades (Tardigrada: Eutardigrada) from the USSR. Boll. Zool. 1992, 59, 95-103. [CrossRef]

22. McInnes, S.J.; Pugh, P.J. Zonation in Antarctic lake-dwelling benthic meiofauna, with emphasis on the Tardigrada. Zool. Anz. 1999, 238, 283-288.

23. Stark, C.; Kristensen, R.M. Tardigrades in the soil of Greenland. Ber. Polarforsch. 1999, 330, 44-63.

24. Schill, R.O.; Huhn, F.; Köhler, H.-R. The first record of tardigrades (Tardigrada) from the Sinai Peninsula, Egypt. Zool. Middle East 2007, 42, 83-88. [CrossRef]

25. Perry, E.S.; Miller, W.R.; Lindsay, S. Looking at tardigrades in a new light: using epifluorescence to interpret structure. J. Microsc. 2015, 257, 117-122. [CrossRef] [PubMed]

26. Morek, W.; Stec, D.; Gąsiorek, P.; Schill, R.O.; Kaczmarek, Ł.; Michalczyk, Ł. An experimental test of eutardigrade preparation methods for light microscopy. Zool. J. Linn. Soc. 2016, 178, 785-793. [CrossRef]

27. Gilbert, J.J. Dormancy in Rotifers. Trans. Am. Microsc. Soc. 1974, 93, 490-513. [CrossRef]

28. Ricci, C. Dormancy patterns in rotifers. Hydrobiologia 2001, 446, 1-11. [CrossRef]

29. Fielding, M.J. Observations on the length of dormancy in certain plant infecting nematodes. Proc. Helminthol. Soc. Wash. 1951, 18, 110-112.

30. Hengherr, S.; Schill, R.O. Dormant stages in freshwater bryozoans-An adaptation to transcend environmental constraints. J. Insect Physiol. 2011, 57, 595-601. [CrossRef]

31. Danks, H.V. Insect Dormancy: An Ecological Perspective; Biological Survey of Canada (Terrestrial Artropods): Ottawa, QC, Canada, 1987.

32. Dahms, H.-U. Dormancy in the Copepoda-An overview. Hydrobiologia 1995, 306, 199-211. [CrossRef] 
33. Lauterborn, R. Demonstrationen aus der Fauna des Oberrheins und seiner Umgebung. Verhandlungen Dtsch. Zool. Ges. 1906, 16, 265-268.

34. Murray, J. The encystment of Macrobiotus. Zoologist 1907, 11, 4-11.

35. Murray, J. Some Tardigrada of the Sikkim Himalaya. J. R. Microsc. Soc. 1907, 27, 269-273. [CrossRef]

36. Murray, J. Scottish Tardigrada, collected by the Lake Survey. Trans. R. Soc. Edinb. 1907, 45, 641-668. [CrossRef]

37. Murray, J. Encystment of Tardigrada. Trans. R. Soc. Edinb. 1907, 45, 837-854. [CrossRef]

38. Murray, J. Tardigrada. In British Antarctic Expedition, 1907-1909: Under the Command of Sir E.H. Shackleton, C.V.O.: Reports on the Scientific Investigations: Biology; Murray, J., Ed.; William Heinemann: London, UK, 1910; Volume 1, pp. 81-185.

39. Heinis, F. Systematik und Biologie der moosbewohnenden Rhizopoden, Rotatorien und Tardigradender Umgebung von Basel mit Berücksichtigung der übrigen Schweiz. Arch. Hydrobiol. Planktonkd. 1910, 5, 40-115.

40. Weglarska, B. Hypsibius (Isohypsibius) smreczynskii spec. nov., a new species of freshwater tardigrade. Zesz. Nauk. Uniw. Jagiellonsk. Pr. Zool. 1970, 16, 107-114.

41. Westh, P.; Kristensen, R.M. Ice formation in the freeze-tolerant eutardigrades Adorybiotus coronifer and Amphibolus nebulosus studied by differential scanning calorimetry. Polar Biol. 1992, 12, 693-699. [CrossRef]

42. Rebecchi, L.; Bertolani, R. Maturative pattern of ovary and testis in eutardigrades of freshwater and terrestrial habitats. Invertebr. Reprod. Dev. 1994, 26, 107-117. [CrossRef]

43. Hansen, J.G.; Kristensen, R.M.; Bertolani, R.; Guidetti, R. Comparative analyses of Bertolanius species (Eohypsibiidae; Eutardigrada) with the description of Bertolanius birnae sp. nov. from northern polar regions. Polar Biol. 2017, 40, 123-140. [CrossRef]

44. Węglarska, B. On the encystation in Tardigrada. Zool. Pol. 1957, 8, 315-325.

45. Szymanska, B. Encystment in the Tardigrade Dactylobiotus dispar (Murray, 1907)(Tardigrada: Eutardigrada). Part I. Observation of living animals and structure of cyst. Zool. Pol. 1995, 40, 91-102.

46. Rost-Roszkowska, M.M.; Poprawa, I. Ultrastructure of the midgut epithelium in Dactylobiotus dispar (Tardigrada: Eutardigrada) during encystation. Zool. Pol. 2008, 53, 19-25. [CrossRef]

47. Hansen, J.; Katholm, A.K. A study of the genus Amphibolus from Disko Island with special attention on the life cycle of Amphibolus nebulosus (Eutardigrada: Eohypsibiidae). In Arctic Biology Field Course, Quqertarsuaq, 2002; Hansen, J.G., Ed.; Zoological Museum University of Copenhagen: Copenhagen, Denmark, 2002; pp. 129-163.

48. Pigoń, A.; Węglarska, B. The respiration of Tardigrada: a study in animal anabiosis. Bull. Acad. Polon. Sci. 1953, 1, 69-72.

(C) 2020 by the authors. Licensee MDPI, Basel, Switzerland. This article is an open access article distributed under the terms and conditions of the Creative Commons Attribution (CC BY) license (http://creativecommons.org/licenses/by/4.0/). 